\title{
POST-COVID ANXIETY AND STRESS AMONG COVID-19 RECOVERED PATIENTS
}

\author{
Ahmad Bilal \\ Assistant Professor, Department of Applied Psychology, \\ The Islamia University of Bahawalpur, Pakistan \\ ahmadbilal4@gmail.com \\ Sehrish Wazir \\ Lecturer, Department of Applied Psychology, \\ Government Sadiq Women University, Pakistan. \\ sehrishwazir15@gmail.com \\ Minahil Aamir \\ Research Scholar, Department of Applied Psychology, \\ The Islamia University of Bahawalpur, Pakistan \\ minahil.aamir99@gmail.com
}

\begin{abstract}
The COVID-19 pandemic is not over yet. And as much as the pandemic has had its effect in real-time, it is leaving behind its traces as well. The most prominent being the various types of stress and anxiety disorders that are now being found in a majority of the individuals, who have either suffered from COVID themselves or have witnessed it first-hand through a loved one. This study aims to find association between post COVID anxiety and stress and its association with demographic variables in people recovered from COVID-19. Based on the survey that was conducted, it was deduced that the majority of the volunteers were suffering from some sort of post-COVID stress and anxiety disorder. Women being large in number as compared to men. Most of the participants were involved in compulsive checking, avoidance behavior, self-monitoring and self-diagnosis in fear of contracting the virus again. People who had the worst COVID symptoms and were in the intensive care unit showed more stress levels than the rest. And healthcare workers showed relatively less, possibly because of their expertise in the management and containing the disease. The majority of the People were not aware of the post-COVID health conditions, collectively termed as Long COVID.
\end{abstract}

Keywords: Post-COVID Anxiety, Post-COVID Stress, Long COVID, Pakistan

\section{INTRODUCTION}

Pandemic is an outbreak of a disease that occurs over a wide geographic area (such as multiple countries or continents) and typically affects a significant proportion of the population (Merriam, 2021). Throughout human history, global pandemics such as cholera, plague, smallpox, and influenza have devastated humanity and killed over 300 to 500 million people (Rosenwald, 2021). First recorded pandemic in human history dates back to $6^{\text {th }}$ Century AD when plague spread like wildfire across Europe, Asia, North Africa and Arabia and killed almost half of the world's population (Horgan, 2014). Another pandemic of significant proportion, Black death, in the 14th century killed almost 200 million people around the globe. Similarly, Spanish flu in the early $20^{\text {th }}$ century infected about 500 million people or one-third of the world's population with an estimated fatality of around 50 million worldwide (CDC, 2019). All these pandemics significantly altered the day to day living in those times and left everlasting effects on human history.

Twentieth century's second half saw unparalleled advances in science and technology. Especially medical sciences witnessed unprecedented and breakthrough advances like mapping of human genome, emergence of magnetic resonance imaging techniques and gene therapies etc. These developments created a sense of complacency among masses making them to believe that any future disease outbreak will be managed effectively. Successful containment of HIV and Dengue fever further cemented this false sense of security. 
Then came December 2019 and the entire world got changed for the times to come. Coronavirus outbreak began in Wuhan city in China in December 2019 and from there on plunged the entire world into chaos. Europe and America, despite being at the pinnacle of technological advancements, bowed down to the devastations of COVID-19. Financial, economic, political and educational institutions melted down to the threats of COVID-19 and the very social fabric of human society got shaken up from its very core.

The World Health Organization declared the outbreak a Public Health Emergency of International Concern on 30 January 2020, and later on 11 March 2020 it was declared a pandemic (Cucinotta \& Vanelli, 2020). Regardless of current advances in medication, COVID-19 caused more than 4 million deaths in under a year (World Health Organization, 2021). Monitoring the trends of its spread, WHO warned the World about the acceleration of COVID-19 pandemic as in 67 days the confirmed number of cases reached 100,000, then it took another 11 days to reach the 2nd 100,000 . For the 3 rd 100,000 it took 4 days and just in a matter of 2 days the infection rate climbed to the 4th 100,000 (Jabeen et al., 2020).

At present, the total number of confirmed cases stands at 207 million, the Global death toll stands at 4.35 Million and the infection is still spreading due to emergence of mutant strains of SARS CoV-2. In addition to causing a huge number of deaths, the pandemic has caused serious physical, economic, financial and emotional problems around the world.

First case of COVID-19 in Pakistan was notified in February 2020. Like other countries in the World, Pakistan was put in the state of high alert. Initially, preventive measures like wearing of face mask and social distancing were advocated by both the Government and the health professionals. Afterwards, these protective measures were intensified due to the increasing number of reported cases with enforcement of complete lockdown, closure of businesses and mosques, social distancing and restriction of movements. Additionally, work from home and office working with reduced staffing level was put into effect. By far, Pakistan has fared well in limiting the rate of acceleration of this pandemic. However, the precautionary measures aimed at reducing the further spread of disease also has the potential to lead to psychological and mental health problems.

Earlier studies have shown that adverse and crisis situations, like the COVID-19 pandemic, greatly affect the emotional and psychological wellbeing of people (Kang et al., 2020; Mukhtar, 2020). According to a report published in The Lancet, people who contracted COVID-19 have doubled risk of developing a mental health issue like anxiety (Post Traumatic Stress Disorder) and depression (Taquet et al., 2020). Researches have shown that 1 in 3 people are anxious due to COVID-19 and a number of people across the Globe are now being diagnosed with depression, sleep problems, stress and different anxiety disorders.

A new study at Oxford University showed that one in three people developed psychiatric conditions post COVID, anxiety disorders being the most common of all. About 1 in 3 people have developed an anxiety disorder after recovering from COVID-19. Anxiety disorders are episodes of intense fear, worry and panic about everyday situations that interfere with daily activities or normal routine of life (Taquet et al., 2020).

Clinicians around the Globe have diagnosed a range of anxiety disorders among COVID patients such as Obsessive-compulsive disorder, Panic disorder, Post-traumatic stress disorder and Post-COVID Anxiety syndrome. Post-COVID Anxiety syndrome has been defined as constantly worrying about catching the virus, be it a loved one or anyone around them, and adopting coping behaviors that include avoidance of certain situations, inability to leave the house, frequent symptom checking and attention to threat (Kingston University, 2021).

It has also been found that a number of people who have recovered from COVID-19 are suffering from Post-COVID Stress disorder. Post-COVID Stress disorder (PCSD) is a subset of Posttraumatic stress disorder (Bradt, 2021). The traumatic event in case of PCSD is the COVID-19 pandemic. PCSD has symptoms just like PTSD, having flashbacks, nightmares, insomnia and painful emotions related to COVID-19. Those who have suffered from COVID-19 or been in direct contact with those who have had COVID-19 or lost their loved ones to it develop PCSD (Prime Genesis, 2021).

Due to the arrival of COVID-19 vaccines, different countries have eased the COVID-19 restriction protocols. As the vaccine doses are being administered, countries like the UK have lifted restrictions while still being mindful of safety. Yet some people find it hard now to go back to their 
old routines and mix with other people as they associate this concept with fear and anxiety. Scientists are calling this the "Post-COVID Anxiety Syndrome" (Drake, 2021). Furthermore, lot of people do recover from COVID-19 usually within 14-15 days of treatment, however, some people do not recover completely and continue having physical or psychological problems. These post- COVID conditions show a range of symptoms that can last for weeks or months (CDC, 2019). These postCOVID health conditions are called The Long COVID Syndrome and its symptoms include; extreme tiredness (fatigue), brain fog, chest tightness, palpitations, muscle and joint pains, anxiety and depression, PTSD, tinnitus, diarrhea, migraine, lung and kidney problem, sleep issues and so on (NHS, 2021).

\section{Hypotheses}

This research focused on knowing how anxiety and stress are associated in people recovered from COVID-19 and the effect of demographics on that association. It was hypothesized that:

1. Patients recovered from COVID-19 suffer from anxiety and stress.

2. Women develop more anxiety disorders after recovering from COVID-19 as compared to men.

3. The level of post-COVID stress and anxiety varies in different age groups.

4. Health care workers have more post-COVID Stress as compared to others.

\section{METHODOLOGY}

\section{Research design and participants}

An online survey was made and sent to those who had contracted COVID-19 since the onset of the pandemic and have recovered from it. The form contained an informed consent, questions about demographics and two scales to measure anxiety and stress. People from all over Pakistan of age 18+ and of every profession and gender participated. A total of $(n=405)$ participated.

\section{Measures}

Two scales were used in this research:

1. COVID Anxiety Scale (CAS)

CAS is a self-report measure containing a 7-item likert type format. The scale assesses specific type of anxiety i.e COVID-19 pandemic related anxiety. The internal consistency of the Urdu scale was .75 Cronbach Alpha (Hussain \& Ahmad, 2021).

2. COVID Stress Scale (CSS)

CSS, COVID Stress scale, is based on a 5-factor model containing a total of 36 items rated on a 5 point likert scale ranging from 0 (not at all) to 4 (extremely). The factors measured are:

- COVID danger and contamination (fear of coming in contact with contaminated surfaces or objects),

- Fear about socio-economic consequences of pandemic (such as loss of job),

- Disease related Xenophobia,

- Compulsive checking and reassurance-seeking behavior regarding possible COVIDthreats,

- Traumatic stress symptoms (nightmares, intrusive thoughts) (Taylor et al., 2020).

The Cronbach alpha coefficients for each scale in each sample was $>.80$, indicating excellent internal consistency. The Cronbach alpha reliability of the Urdu scale was .79.

\section{Procedure}

Before surveying, formal permission was taken from the Research Ethics Committee of the department to conduct the study. The questionnaire was made and distributed among participants using Google forms. Data was gathered after seeking permission from the supervisor. The form took about 15 to 20 minutes to fill.

\section{Ethical Considerations}

An informed consent was attached to the survey form stating the purpose and nature of the study. The informed consent also ensured confidentiality and their right to withdraw from the research at any time. Data from willing participants was obtained only.

\section{DATA ANALYSIS}


The data obtained from the responses of the survey was analyzed by the Statistical Software for the Social Sciences (SPSS), v25, with the help of a statistician. The results have been demonstrated in the form of frequency of demographic variables, correlation, $t$ test and analysis of variance.

\section{RESULTS}

Table No. 1 Frequency Distribution of Demographic Variables $(n=405)$

\begin{tabular}{|c|c|c|c|}
\hline Demographic Variables & Characteristics & $\mathbf{F}$ & $\%$ \\
\hline \multirow[t]{2}{*}{ Gender } & Male & 199 & 49.1 \\
\hline & Female & 206 & 50.9 \\
\hline \multirow[t]{5}{*}{ Age (years) } & $18-25$ & 51 & 12.6 \\
\hline & $26-35$ & 82 & 20.2 \\
\hline & $36-45$ & 137 & 33.8 \\
\hline & $46-55$ & 106 & 26.2 \\
\hline & $55+$ & 29 & 7.2 \\
\hline \multirow[t]{6}{*}{ Education } & Govt Employee & 100 & 24.7 \\
\hline & Private Employee & 48 & 11.9 \\
\hline & Entrepreneur & 59 & 14.6 \\
\hline & Health Care Workers & 66 & 16.3 \\
\hline & Student & 51 & 12.6 \\
\hline & Others & 81 & 20.0 \\
\hline \multirow[t]{4}{*}{ Marital Status } & Married & 258 & 63.7 \\
\hline & Single & 125 & 30.9 \\
\hline & Widow & 15 & 3.7 \\
\hline & Divorced & 7 & 1.7 \\
\hline
\end{tabular}

Table 1 gives the frequency distribution of demographic variables included in the study. There are around $49 \%$ males and $51 \%$ are female participants. Majority of the participants (34\%) are from the 36-45 years age group followed by around $26 \%$ who are from the $46-55$ years age group whereas only $20 \%$ participants are from the 26-35 years age group. $25 \%$ of the participants have government jobs, and $16 \%$ are health care workers. Around $64 \%$ participants are married whereas $31 \%$ are single participants.

Table No. 2 Correlation between COVID anxiety and COVID stress $(n=405)$

\begin{tabular}{lccccc}
\hline Variables & M & & SD & $\mathbf{1}$ & $\mathbf{2}$ \\
\hline COVID 19 Anxiety & & 12.11 & 2.57 & - \\
COVID 19 Stress & & 26.08 & 7.56 & $.52^{* *}$ & \\
\hline
\end{tabular}


$* * p<.01$

Table 2 describes the correlation for testing a relationship between COVID 19 anxiety and COVID 19 stress. There is a statistically significant positive relationship between COVID 19 anxiety and COVID 19 stress. The increase in anxiety would also increase stress and vice versa.

Table No. 3 Result of $t$ Test $(n=405)$

Gender $\quad$ Male $(n=199) \quad$ Female $(n=206)$

\begin{tabular}{lcccccccc}
\hline Variables & M & SD & M & SD & \multicolumn{1}{l}{ df } & \multicolumn{2}{c}{ Sig. } \\
\hline COVID 19 Anxiety & 11.59 & 2.52 & 12.62 & 2.52 & -4.10 & 403 & .000 \\
\hline COVID 19 Stress & 24.53 & 7.95 & 27.57 & 6.85 & -4.11 & 390.03 & .000
\end{tabular}

The Table 3 gives the results of $t$ test computed to find out gender differences in COVID 19 anxiety and COVID 19 stress. The results of $t$ test are statistically significant. The females have more COVID 19 anxiety and COVID 19 stress as compared to males.

Table No. 4 Analysis of Variance for Age Group Differences

\begin{tabular}{|c|c|c|c|c|c|c|c|c|}
\hline Age Group & & $18-25$ & $26-35$ & $36-45$ & $46-55$ & $55+$ & F (4) & Sig. \\
\hline Variables & & $\mathbf{M}(\mathbf{S D})$ & M (SD) & $\mathbf{M}(\mathbf{S D})$ & M (SD) & M (SD) & & \\
\hline $\begin{array}{l}\text { COVID } \\
\text { Anxiety }\end{array}$ & 19 & $\begin{array}{l}11.31 \\
(2.75)\end{array}$ & $\begin{array}{l}11.57 \\
(2.52)\end{array}$ & $\begin{array}{l}12.26 \\
(2.14)\end{array}$ & $\begin{array}{l}12.44 \\
(2.41)\end{array}$ & $\begin{array}{l}13.17 \\
(3.94)\end{array}$ & 4.03 & .003 \\
\hline $\begin{array}{l}\text { COVID } \\
\text { Stress }\end{array}$ & 19 & $\begin{array}{l}26.52 \\
(9.27)\end{array}$ & $\begin{array}{l}24.00 \\
(7.43)\end{array}$ & $\begin{array}{l}26.47 \\
(6.69)\end{array}$ & $\begin{array}{l}26.19 \\
(7.13)\end{array}$ & $\begin{array}{l}28.89 \\
(9.01)\end{array}$ & 2.74 & .02 \\
\hline
\end{tabular}

Table 4 describes the results of ANOVA computed to find age wise differences in COVID 19 anxiety and COVID 19 stress. The results of ANOVA are statistically significant for both COVID 19 anxiety and COVID 19 stress. The individuals of age groups 46-55 and 36-45 have more COVID 19 anxiety as compared to other age groups. On the other hand, individuals of 55+ age groups have more COVID 19 stress.

Table No. 5 Analysis of Variance for Profession Wise Differences

\begin{tabular}{|c|c|c|c|c|c|c|c|c|}
\hline Profession & $\begin{array}{l}\text { Govt. } \\
\text { Emp }\end{array}$ & $\begin{array}{l}\text { Private } \\
\text { Emp }\end{array}$ & Enterpr. & HCW & Students & Others & $\mathbf{F}(\mathbf{5})$ & Sig. \\
\hline Variables & M (SD) & M (SD) & $\mathbf{M}(\mathbf{S D})$ & M (SD) & M (SD) & & & \\
\hline $\begin{array}{l}\text { COVID } \\
\text { Anxiety }\end{array}$ & $\begin{array}{l}12.15 \\
(2.18)\end{array}$ & $\begin{array}{l}11.39 \\
(3.36)\end{array}$ & $\begin{array}{r}11.83 \\
(12.08)\end{array}$ & $\begin{array}{l}11.72 \\
(1.91)\end{array}$ & $\begin{array}{l}11.37 \\
(2.71)\end{array}$ & $\begin{array}{l}13.49 \\
(2.62)\end{array}$ & 7.21 & .000 \\
\hline $\begin{array}{l}\text { COVID } 19 \\
\text { Stress }\end{array}$ & $\begin{array}{l}26.76 \\
(6.53)\end{array}$ & $\begin{array}{l}22.66 \\
(8.23)\end{array}$ & $\begin{array}{l}25.66 \\
(6.63)\end{array}$ & $\begin{array}{l}25.09 \\
(6.83)\end{array}$ & $\begin{array}{l}25.76 \\
(9.35)\end{array}$ & $\begin{array}{l}28.58 \\
(7.52)\end{array}$ & 4.33 & .001 \\
\hline
\end{tabular}

Table 5 describes the results of ANOVA computed to find profession wise differences in COVID 19 anxiety and COVID 19 stress. The results of ANOVA are statistically significant. The professionals other than health care workers had the greatest anxiety and stress as compared to students and private professionals.

\section{DISCUSSION}


This study aimed at investigating the association of post COVID anxiety and stress with gender, age, and profession. As the post COVID conditions included a broad range of new health problems, the study around this specific domain was of great significance. This pandemic led many people to varied forms of mental health problems, which includes depression, various types of anxiety and stress related disorders (Tucker \& Czapla, 2021). People who did not even experience COVID -19 symptoms despite being infected, or in other words, were asymptomatic, had also post COVID health conditions either physiologically or psychologically. (CDC, 2019).

'Long haulers' is the name given to those who experience symptoms long after testing negative from COVID-19. This suffering is known as 'Long COVID' (Tucker \& Czapla, 2021). The virus can damage the brain, heart, kidneys and especially lungs which can result in lifelong health problems (Mayo Clinic, 2021). There are a number of symptoms and lingering problems such as body-aches, fatigue, shortness of breath, brain fog, COVID toes, loss of smell or taste for long time, myocarditis, migraine, sleep disturbances, PTSD, depression, anxiety disorders, difficulty concentrating. Research suggests that approximately 10 percent of people will become 'long haulers'(Cleveland Clinic, 2021).

The Office for National Health Statistics estimates that about 1.1 million people in the UK reported symptoms of Long COVID Syndrome (Office of National Statistics UK, 2021). One study in Wuhan, China (the city of the first outbreak) found that $76 \%$ of patients hospitalized with COVID-19 were still experiencing symptoms six months after they were infected. A report at CNN showed that researchers who followed people infected with COVID-19 for up to 9 months found that $30 \%$ of the patients were still reporting symptoms and more than half reported a worse quality of life than before (Gupta, 2021). Another research shows that one in five people with coronavirus develop long term symptoms (BBC, 2021). Different mental health issues can arise from the loss and grief, fatigue and the unresolved pain and trauma (PTSD) after long treatment, especially, at an intensive care unit (John Hopkins Medicine, 2021).

Large number of studies have looked into the aftermath of COVID-19, specifically related to psychological disorders and mental health conditions (Duan \& Zhu, 2020). The pandemic not only gave rise to morbidity but also to various psycho-socio problems. Lack of interpersonal support played an important role in the rise of stress among COVID-19 positive patients that, in turn, caused anxiety, post-traumatic stress disorder, distress, burnout, and other psychological problems (Karimi et al., 2020).

According to a recent observation, fear of COVID-19 is associated more with anxiety and stress. (Bitan et al., 2020) and cases of suicides have also been reported in the population due to fear of COVID-19 (Mamun \& Griffiths, 2020). The cases of suicide associated with COVID-19 fear have been reported in India, Bangladesh and Pakistan (Goyal et al., 2020). Over 23 cases of suicide were linked with COVID-19 fear and the stress induced due to lockdown in Pakistan, out of which 4 were suspected cases and the rest were confirmed with testing positive (Mamun \& Griffiths, 2020).

Adapting to the 'new normal' has been difficult for some individuals as there had been a great change to the routines since the onset of the pandemic. The 'eventual return' to some kind of societal functioning is likely to expose an individual to an increased risk of infection such as workplace, family gatherings, recreational activities. For some individuals, it is difficult to return to these societal engagements due to maladaptive forms of coping in an attempt to reduce the distress caused by this anxiety (Goyal et al., 2020). This anxiety has been termed as 'Post-COVID Anxiety Syndrome'. The results from this research also showed that the majority of the participants now avoid going to restaurants and other public places. They stock up on household and grocery items in the fear of lockdown.

Post COVID Anxiety Syndrome and Post-COVID Stress Disorder are new terms that have emerged during this time and little is known about them. In this research, CAS (COVID-anxiety scale) was used to gauge the post-COVID anxiety symptoms and behavior. COVID Stress Scale (CSS) was used to see stress among the recovered patients.

The study hypothesized that people who recovered from COVID-19 were most likely to have anxiety and stress. The stress and anxiety can be for a number of reasons including one's own health, safety of loved one's or socio-economic conditions. People who remained at an intensive care unit or were hospitalized had more stress as compared to those who stayed at home. The fear of getting re- 
infected and being isolated also contributes to the stress. Those who had lost a loved one while they were in isolation showed signs of PTSD and high stress (Toquet, 2020).

Another hypothesis was made that women have higher levels of stress and develop more anxiety disorders as compared to men after recovering from COVID-19. It is known through different researches that women are at more risk of developing psychological issues as compared to men due to biological, and sociological reasons (Mental Health Foundation, 2021). It was noticed that women spend more time on the internet and related activities such as social questioning, blogging, media-sites sharing as compared to men. The results from COVID Stress Scale (CSS) showed that women searched the internet for information about COVID more than men did and watched Youtube videos about COVID. This can be another reason why women are more stressed as all sorts of information, good or bad, is easily available on the internet regarding COVID-19.

During this pandemic, the front-liners, health workers have been in great stress and agony. The uncertainty in the emergency departments of hospitals and clinics came with great stress especially with an unknown threat to their own lives. About $16 \%$ of healthcare workers participated in this research. It was seen that the majority of healthcare workers who participated were worried about contracting the virus again and were more worried on how to keep their loved ones safe. This can be due to the reason that they work in hospitals and intensive care units with COVID-19 patients. They can be carriers of the virus and spread it to their family when they go back home. It was also seen that the majority of the healthcare workers believed that only social distancing was not enough. A combination of social distancing and basic hygiene, both are necessary for protection against the virus. According to World Health Organization guidelines, a distance of at least 1-metre is important to reduce the risk of getting infected by another person's cough or sneeze along with washing hands and wearing a mask (WHO, 2020).

When comparing stress and anxiety levels among healthcare workers and participants of other professions, it was observed that people belonging to other professions (Government employees, employees of private organizations, students, entrepreneurs and others) were more affected by COVID stress and anxiety. One of the reasons for this can be that healthcare workers are more aware of the disease and its management whereas those belonging to other professions might not be as educated or aware about it. Another reason for stress can be financial insecurity and fear of unemployment (OECD, 2021).

Age group difference was also taken into account to see which age group is suffering from more stress and anxiety. It was seen that participants of age group 36 to 45 and 45 to 55 showed high levels of Post-COVID anxiety. This can be due to the reason that the majority of these participants belong to the working class and have a family to look after. The post-COVID health effects cause hindrance in their quality of work and some might have lost their jobs because of it. Other anxietyinducing factors can include; concern about personal finances, being unable to enjoy outdoor activities due to lockdown restrictions or fatigue after recovering, worrying about keeping a loved one safe from the virus. The age group of adults who were 55+ were seen to have more post-COVID stress as compared to any other age group. Older adults living independently or living in old homes can be stressed as contact with children, friends, and relatives becomes less and limited. This can lead to loneliness and depression (Chamberlain et al., 2021). Another reason for stress can be that research has shown that old-aged adults are at a higher risk of developing a serious medical condition that can, in some cases, become life-threatening (CDC, 2019).

\section{Limitations}

1. The number of respondents reached was less as the study conducted was online. People having smartphones could participate only.

2. The number of items in the survey were 43 which made the survey lengthy and time-taking. This posed a problem as respondents easily lost attention and interest.

\section{Recommendations}

1. Future research should include more respondents from different spheres of life including the blue-collar workers. 
2. The length of the questionnaire be kept short so that respondents do not lose attention and interest.

\section{CONCLUSION}

Due to its exogenous nature, COVID-19 pandemic has given a unique opportunity to scientists and researchers to study human behavior and reaction to extreme events. This particular research also aimed at finding association of stress and anxiety among those who recovered from COVID-19. It was observed that the majority of the participants who had tested positive are suffering from some post-COVID health condition, especially anxiety and stress which lead to adaptation of some maladaptive coping behavior such as avoidance, checking, worrying and threat monitoring. It was also seen that people adopt avoidance behavior to help themselves deal with anxiety, such as avoiding going to restaurants and using elevators. Differences in age group, and gender show statistical variation with young adults and women scoring high on anxiety scale. More research is needed on how to manage the symptoms, the anxiety and the stress that comes along with COVID. Awareness programs and informatory sessions with healthcare providers and researchers can help people become more aware of Long COVID and how to live with the new normal.

\section{REFERENCES}

BBC News. (2021). Long Covid: What is it and what are the symptoms. https://www.bbc.com/news/health-57833394

Bitan, D. T., Grossman-Giron, A., Bloch, Y., Mayer, Y., Shiffman, N., \& Mendlovic, S. (2020). Fear of COVID-19 scale: Psychometric characteristics, reliability and validity in the Israeli population. Psychiatry research, 289, 113100. https://doi.org/10.1016/j.psychres.2020.113100

Bradt, G. (2021). Helping Colleagues with Post-COVID Stress Disorder (PCSD). Forbes. https://www.forbes.com/sites/georgebradt/2021/03/23/post-covid-stress-disorder-pcsd-andhow-to-help-those-with-it/?sh=488beb7c5346

Centre for Disease Control and Prevention (2019). Post COVID Conditions. https://www.cdc.gov/coronavirus/2019-ncov/long-term-effects.html

Chamberlain, S., Grant, J., Trender, W., Hellyer, P., \& Hampshire, A. (2021). Post-traumatic stress disorder symptoms in COVID-19 survivors: Online population survey. British Journal of Psychiatry Open, 7(2), E47. doi:10.1192/bjo.2021.3

Cleveland Clinic (2021). What it means to be a Coronavirus 'Long-Hauler'. https://health.clevelandclinic.org/what-it-means-to-be-a-coronavirus-long-hauler/

Cucinotta, D., \& Vanelli, M. (2020). WHO Declares COVID-19 a Pandemic. Acta bio-medica : Atenei Parmensis, 91(1), 157-160. https://doi.org/10.23750/abm.v91i1.9397

Drake, K. (2021, May 7). Medical News Today: COVID-19 Syndrome- a pandemic phenomenon? https://www.medicalnewstoday.com/articles/covid-19-anxiety-syndrome-a-pandemicphenomenon\#Possible-causes-of-COVID-19-anxiety

Duan, L., \& Zhu, G. (2020). Psychological interventions for people affected by the COVID-19 epidemic. Lancet Psychiatry, 7, 300-302. doi: 10.1016/S2215-0366(20)30073-0

Goyal, P., Choi, J. J., Pinheiro, L. C., Schenck, E. J., Chen, R., Jabri, A., Satlin, M. J., Campion, T. R., Jr, Nahid, M., Ringel, J. B., Hoffman, K. L., Alshak, M. N., Li, H. A., Wehmeyer, G. T., Rajan, M., Reshetnyak, E., Hupert, N., Horn, E. M., Martinez, F. J., Gulick, R. M., ... Safford, M. M. (2020). Clinical Characteristics of Covid-19 in New York City. The New England journal of medicine, 382(24), 2372-2374. https://doi.org/10.1056/NEJMc2010419

Gupta, S. (2021). Almost a third of people with 'mild' Covid-19 still battle symptoms months later, study finds. https://edition.cnn.com/2021/02/19/health/post-covid-syndrome-long-haulersgupta-wellness/index.html

Horgan, J. (2014). Justinian plague, World History Encyclopedia. https://www.worldhistory.org/article/782/justinians-plague-541-542-ce/

Hussain, S., \& Ahmad, S. (2021). The development of Coronavirus Anxiety Scale in Urdu (CASU). Journal of Pakistan Psychiatric Society, 18 (1), 1-4.

Jabeen, A., Ansari, J.A., Ikram, A., Abbasi, S.H., Khan, M.A., Rathore, T.R., \& Safdar, M. (2020). Comparison of actions taken by Pakistan, United Arab Emirates and Vietnam for COVID-19 
prevention and control. Global Biosecurity, 2(1), p.None.

DOI: http://doi.org/10.31646/gbio.79

John Hopkins Medicine (2021). COVID Long Haulers: Long term effects of COVID-19.

https://www.hopkinsmedicine.org/health/conditions-and-diseases/coronavirus/covid-longhaulers-long-term-effects-of-covid19

Kang, L., Li, Y., Hu, S., Chen, M., Yang, C., Yang, B. X., Wang, Y., Hu, J., Lai, J., Ma, X., Chen, J., Guan, L., Wang, G., Ma, H., \& Liu, Z. (2020). The mental health of medical workers in Wuhan, China dealing with the 2019 novel coronavirus. Lancet Psychiatry, 7(3), e14. doi: 10.1016/S2215-0366(20)30047-X

Karimi, Z., Fereidouni, Z., Behnammoghadam, M., Alimohammadi, N., Mousavizadeh, A., Salehi, T., Mirzaee, M. S., \& Mirzaee, S. (2020). The Lived Experience of Nurses Caring for Patients with COVID-19 in Iran: A Phenomenological Study. Risk management and healthcare policy, 13, 1271-1278. https://doi.org/10.2147/RMHP.S258785

Kingston University (2021). COVID-19 anxiety syndrome. https://www.kingston.ac.uk/news/article/2490/05-may-2021-covid19-anxiety-syndrome-mayprevent-people-from-returning-to-normal-living-after-pandemic-new-research

Mamun, M. A., \& Griffiths, M. D. (2020). First COVID-19 suicide case in Bangladesh due to fear of COVID-19 and xenophobia: possible suicide prevention strategies. Asian Journal of Psychiatry, 51, 102073. doi: 10.1016/j.ajp.2020.102073

Mayo Clinic (2021). COVID-19 (Coronavirus): Long Term Effects. https://www.mayoclinic.org/diseases-conditions/coronavirus/in-depth/coronavirus-long-termeffects/art-20490351

Mental Health Foundation (2021). Women and mental health. https://www.mentalhealth.org.uk/a-toz/w/women-and-mental-health

Merriam-Webster. (n.d.). Pandemic. In Merriam-Webster.com dictionary. Retrieved August 15, 2021, from https://www.merriam-webster.com/dictionary/pandemic

Mukhtar, S. (2020). Pakistanis' mental health during the COVID-19. Asian Journal of Psychiatry, 51(10), 21-27. doi: 10.1016/j.ajp.2020.102127

National Health Services (2021). Long term Effects of Coronavirus (Long COVID). https://www.nhs.uk/conditions/coronavirus-covid-19/long-term-effects-of-coronavirus-longcovid/

Office for National Statistics UK (2021). Updated estimates of the prevalence of long COVID symptoms. https://www.ons.gov.uk/search?q=long+covid

Organization for Economic Co-operation and Development (2021). Tackling the mental health impact of the COVID-19 crisis: An integrated, whole-of-society response.

https://www.oecd.org/coronavirus/policy-responses/tackling-the-mental-health-impact-of-thecovid-19-crisis-an-integrated-whole-of-society-response-0ccafa0b/

Prime Genesis (2021). Helping Colleagues with Post COVID Stress Disorder. https://www.primegenesis.com/our-blog/2021/03/helping-colleagues-with-post-covid-stressdisorder-pcsd/

Rosenwald, M. S. (2021). History's deadliest pandemics. Washington post https://www.washingtonpost.com/graphics/2020/local/retropolis/coronavirus-deadliestpandemics/

Taquet, M., Luciano, S., Geddes, J. R., \& Harrison, P. J. (2020). Bidirectional associations between COVID-19 and psychiatric disorder, The Lancet psychiatry. https://doi.org/10.1016/S22150366(20)30462-4

Taylor, S., Landry, C. A., Paluszek, M. M., Fergus, T. A., McKay, D., \& Asmundson, G. (2020). Development and initial validation of the COVID Stress Scales. Journal of anxiety disorders, 72, 102232. https://doi.org/10.1016/j.janxdis.2020.102232

Tucker, P., \& Czapla, C. S. (2021). Post-COVID Stress Disorder: another emerging consequence of COVID. Psychiatric Times, 38(1). https://www.psychiatrictimes.com/view/post-covid-stressdisorder-emerging-consequence-global-pandemic

World Health Organisation (2020). WHO Declares COVID-19 a Pandemic. https://www.ncbi.nlm.nih.gov/pmc/articles/PMC7569573/ 
Bilal, Wazir, \& Aamir

World Health Organisation (2021). Coronavirus Disease 2019: advice for the public.

https://www.who.int/emergencies/diseases/novel-coronavirus-2019/advice-for-public. 